\title{
Phytochemistry and antimicrobial property of fruits of Chrysophyllum albidum against selected clinical isolates
}

\author{
Adeleye S.A. ${ }^{\text {, }}$, Orji, C.C. ${ }^{\mathrm{b}}$, Braide W. ${ }^{\mathrm{c}}$ and Akaluka C.K. ${ }^{\mathrm{d}}$
}

Federal University of Technology Owerri, PMB 1526, Owerri, Imo state, Nigeria

aadeleyesamuela@gmail.com*, bgodledone@gmail.com, cwesleybraide2005@yahoo.com, cynthia.akaluka@futo.edu.ng

Keywords: Qualitative Phytochemistry, Antimicrobial, susceptibility, Chrysophyllum albidum, Assay.

Abstract. The antimicrobial activity of methanolic and aqueous extracts of Chrysophyllum albidum fruits was investigated against clinical isolates(Staphylococcus aureus, Escherichia coli, Klebsiella pneumonia and Candida albicans). Qualitative phytochemistry of the plant indicated that the plant contained Flavonoids, Steroids, Alkaloids, Tannin, Anthraquinone and Cardiac glycosides while Saponins were reported absent. The maximum activity of the aqueous extracts in the test isolates was observed on Staphylococcus aureus, which showed clear zones with diameters of $24.0 \mathrm{~mm}$, $20.0 \mathrm{~mm}$ and $16.5 \mathrm{~mm}$ at concentrations of $100 \mathrm{mg} / \mathrm{ml}, 50 \mathrm{mg} / \mathrm{ml}$ and $25 \mathrm{mg} / \mathrm{ml}$ respectively while it had low activity on Klebsiella pneumonia, with clear zones of inhibition of $15.0 \mathrm{~mm}, 12.0 \mathrm{~mm}$ and $10.5 \mathrm{~mm}$ at same concentrations. On the other hand, Methanolic extracts activity on Staphylococcus aureus produced clear zones of $21.0 \mathrm{~mm}, 17.5 \mathrm{~mm}$ and $12.0 \mathrm{~mm}$ at concentrations of $200 \mathrm{mg} / \mathrm{ml}$, $100 \mathrm{mg} / \mathrm{ml}$ and $50 \mathrm{mg} / \mathrm{ml}$ respectively as its best activity while the it had least observed activity on Klebsiella pneumonia with clear zones of $14.0 \mathrm{~mm}, 11.5 \mathrm{~mm}$ and $10.5 \mathrm{~mm}$ at same concentrations. The aqueous extracts had greater activity than the methanolic extracts at same concentrations. Therefore, the fruit of the plant can be a good source of remedy in phytomedicine.

\section{Introduction}

Healing with medicinal plants is as old as mankind itself [1]. The connection between man and his search for drugs in nature dates from the far past, of which there is ample evidence from various sources: written documents, preserved monuments and even original plant medicines. Awareness of medicinal plants usage is a result of the many years of struggles against illnesses due to which man learned to pursue drugs in barks, seeds, roots, fruit bodies, leaves and other parts of plants [2]. Medicinal plants are known to owe their curative potentials to certain biological active substances which exist in parts of plants. The chemicals which are referred to as active principles or phytochemical substances include terpenes, flavonoid, bioflavonoid, benzophonones, xanthenes, as well as some metabolites such as tannins, saponins, cyanates, oxalate and anthrax-quinones $[3,4]$. Plants have historically provided a source of inspiration for novel drug compounds, as plant derived medicines have made large contributions to human health and well-being [3]. Their role is two-fold in the development of a medicine, a natural blueprint for the development of new drugs. Their second role is to be used as a phytomedicine for the treatment of disease. The development of phytomedicines follows the ethnomedicinal approach. The first generation of plant drugs were simple botanicals employed in more or less their crude form. Several effective medicines used in their natural state such as cinchona, opium, belladonna and aloe were selected as therapeutic agents based on empirical evidence of their clinical application by traditional societies from different parts of the world [3]. Following the industrial revolution, a second generation of plant based drugs emerged based on scientific processing of the plant extracts to isolate their active constituents. The second generation phytopharmaceutical agents were pure molecules and some of the compounds were even more pharmacologically active than their synthe tic counterparts. Notable examples were quinine from Cinchona, reserpine from Ranolfia, and more recently taxol from Taxus species [3]. 
These compounds differed from the synthetic therapeutic agents only in their origin. They followed the same method of development and evaluation as other pharmaceutical agents. The sequence for development of pharmaceuticals usually begins with the identification of active lead molecules, detailed biological assays and formulation of dosage forms in that order, and followed by several phases of clinical studies designed to establish safety, efficacy and pharmacokinetic profile of the new drug. Possible interaction with food and other medications may be discerned from the clinical trials. In the development of third generation phytotherapeutic agent, a top-bottom approach is usually adopted. This consists of first conducting a clinical evaluation of the treatment modalities and therapy as administered by traditional doctors or as used by the community as folk medicine. This research therefore investigate and evaluate the antimicrobial properties or efficacy of the Chrysophyllum albidum fruit against four pathogenic microbial isolates.

\section{Materials and Method}

\section{Sample collection}

Fresh and ripe Chrysophyllum albidum fruit samples were bought at Eke-Onunwa market in Owerri, Imo state and transported to the laboratory in a bag.

\section{Preparation of sample}

The fruit samples were thoroughly washed with clean water. The seeds were removed and the pulp and peel of the fruit were cut into tiny pieces. The pieces of the sample were then dried and grinded to powder and stored in sterile bottles.

\section{Extraction process}

The extraction process was done by soaking $50 \mathrm{~g}$ of the dried powdered sample in $100 \mathrm{ml}$ of the solvent (distilled water and methanol) for 5 days. The extracts were filtered using Whatman filter paper and allowed to evaporate to dryness. Different concentrations of the extracts were then prepared (25, 50 and $100 \mathrm{mg} / 1$ for aqueous extracts; 50,100 and $200 \mathrm{mg} / 1$ for methanolic extracts).

\section{Qualitative phytochemical Analysis of the Plant material.}

The qualitative methods already established to test for classes of compounds in plant extracts by Ciulei [5] and Chitravadivu et al. [6] were used. The substances that were tested for included: Tanins, Saponins, and Flavonoids, Cardiac glycosides, Alkaloids, Anthraquinone and Steroids which are reported to have biological activities.

\section{a) Test for Anthraquinones}

The determination of Anthraquinones was carried out by the titration method of AOAC [7]. To $1 \mathrm{ml}$ of solution, $5 \mathrm{ml}$ of $10 \%$ HCL was added and allowed to stay for 5 minutes. The solution was filtered. The filtrate was decanted into a test tube and shaken with $5 \mathrm{ml}$ of benzene. The upper benzene layer was pipette off and transferred into test tube containing $5 \mathrm{ml}$ of $10 \%$ ammonium hydroxide. Production of pink, red or violet colouration in the lower ammonia

\section{b) Test for Glycosides}

The determination of Glycosides was carried out by the titration method of AOAC [7]. To $1 \mathrm{ml}$ of the test solution, 2 drops of Conc. Sulphuric acid was added and placed in water bath for about 15 minutes. $20 \% \mathrm{KOH}$ will be added to make the solution alkaline. To this solution, few drops of $\mathrm{FeCl}_{2}$ were added. The formation brick red precipitate indicates the presence of glycosides.

\section{c) Test for alkaloids}

One milligram of dried extract was dissolved in 6 props of $2 \%$ hydrochloric acid. The solution was divided into 3 aliquots; to the first portion which acted as a reference, $2 \mathrm{ml}$ of distilled water was added. To the second test tube, 2 drops of Dragendorff's reagent whose Basic Bismuth nitrate were 
added. A precipitate indicated presence of alkaloids. To the third portion, 2 drops of Mayer's reagent was added and a yellowish white precipitate indicated the presence of alkaloids.

\section{d) Test for flavonoids (shinoda test)}

A little amount of magnesium powder and a few drops of concentrated HCL were added to $3 \mathrm{ml}$ of methanolic extract. A red or intense red coloration indicates the presence of flavonones.

\section{e) Test for tannins}

One milligram of plant extracts was dissolved in $1.5 \mathrm{ml}$ of water; 3 drop of dilute ferric chloride from were added. A blackish blue colour indicated the presence of Gallic tannins and green blackish colour indicated catechol tannins.

\section{f) Test for saponins}

Three drops of dimethylsulfoxide were added to $1 \mathrm{mg}$ of plant extract, $5 \mathrm{ml}$ of distilled water added and shaken. Presence of foam which persisted for more than 15 min indicated the presence of saponins.

\section{g) Test for steroids and triterpenoids}

One milligram of dried extracts was dissolved in $0.5 \mathrm{ml}$ of acetic anhydride; $0.5 \mathrm{ml}$ of chloroform was added. The solution was pipette into a dry test tube and $1 \mathrm{ml}$ of concentrated sulphuric acid added at the bottom of the tube. A brown-red ring at the interface between the two liquids and a green supernatant indicated the presence of steroids and triterpenoids.

\section{Isolation and identification of test organisms Isolation of test organisms}

The test organisms used in the study were isolated from different clinical specimen at Ferdicon medical laboratory in Owerri, Imo state. The bacterial isolate, Escherichia coli was isolated from a faecal specimen, Staphylococcus aureus from sputum, Klebsiella pneumonia from a urine specimen and the fungal isolate, Candida albicans from a vaginal swab. All the test organisms were subcultured to get pure cultures and tested using appropriate biochemical tests. The results obtained was matched with standard identification manuals [8].

\section{Biochemical tests}

Biochemical tests were used in the identification and confirmation of the bacterial isolates in line with standard operational procedures outlined by Cheesbrough [9].

\section{a) Indole test}

This test was used to identify Escherichia coli as it can break down the amino acid tryptophan with the release of indole. The test organism was inoculated into a bijou bottle containing $3 \mathrm{ml}$ of sterile tryptone water and incubated at $35^{\circ} \mathrm{c}$ for up to 48 hours. $0.5 \mathrm{ml}$ of Kovac's reagent was added and shaken gently. A red colour was observed on the surface layer.

\section{b) Catalase and Coagulase test}

This test was used to identify Staphylococcus aureus as a catalase and coagulase enzymes producer. To test for catalase $3 \mathrm{ml}$ of hydrogen peroxide solution was poured into a test tube. The test organism was inoculated into the solution and active bubbling was observed. The ability of the isolate to coagulate horse serum was recorded as coagulase positive.

\section{c) Citrate utilization test}

This test was used to identify Klebsiella pneumonia as it uses citrate as its source of carbon. Slant Simmon's citrate agar was prepared in bijou bottles, and a saline suspension of the test organism was streaked on the slant and also stabbed to the butt. This was incubated at $35^{\circ} \mathrm{c}$ for 48 hours and a bright blue colour was observed. 


\section{Antimicrobial screening}

The antimicrobial properties of the extracts were evaluated using the Kirby-Bauer disc diffusion test. A microbial cell suspension was inoculated into a nutrient agar medium and poured into sterile petri dishes. Sterile paper discs $6 \mathrm{~mm}$ in diameter were impregnated with $20 \mu 1$ of each extract concentration $(25,50$ and $100 \mathrm{mg} / 1$ for aqueous extracts; 50,100 and $200 \mathrm{mg} / 1$ for methanolic extracts), which were prepared using the same solvents employed to dissolve the plant extracts. The impregnated discs were then placed on the inoculated agar surface. Standard Ceftriaxone and Ofloxacine discs were used as positive control while discs loaded with $20 \mu 1$ of solvents were used as negative control. The plates were pre-incubated for 2 hours in a refrigerator and subsequently incubated overnight at $37^{\circ} \mathrm{C}$ for 24 hours. The resulting zones of inhibition were measured and recorded.

\section{Results}

Table 1 shows the qualitative phytochemical analysis of the fruits of Chrysophyllum albidum. From the results, Flavonoids, Steroids, Alkaloids, Tannin, Anthraquinone and Cardiac glycosides were found to be present in the plant's fruit while Saponin was found absent.

Table 1: Qualitative phytochemical analysis of the fruit of Chrysophyllum albidum.

\begin{tabular}{|l|c|}
\hline Phytochemical & Amount \\
\hline Flavonoids & + \\
\hline Saponin & - \\
\hline Steroids & + \\
\hline Tannin & + \\
\hline Alkaloids & + \\
\hline Anthraquinone & + \\
\hline Cardiac glycoside & + \\
\hline \multicolumn{2}{|c|}{ Key: (+) Present, (-) Absent } \\
\hline
\end{tabular}

The result of the antimicrobial screening test showed clear zones of inhibition around the impregnated discs of each of the three concentrations of both the aqueous and methanolic extracts of the Chrysophyllum albidum fruit which were inoculated on all four clinical isolates. The mean zones of inhibition for the aqueous and methanolic extracts are shown in Tables 2 and 3 . The presence of the zones of inhibition is a clear evidence of the antimicrobial properties of the $C$. albidum fruit. The Minimum Inhibitory Concentration (MIC) of both aqueous and methanolic extracts of the C. albidum fruit was also determined from the results of the antimicrobial test. This is shown in Table 4. The results of the test were also analysed statistically using the Analysis of Variance (ANOVA) to check the significance of the variations of the result. Comparison of the observed variance ratio $F_{\mathrm{s}}$ and the conservative critical value as well as the next tabled $F$ with less degree of freedom is convincing enough to reject the null hypothesis for both the aqueous and methanolic extracts. Thus, both results are significant.

\section{Means zones of inhibition}

The tables show the mean zones of inhibition $(\mathrm{mm})$ of each of the three concentrations of the discs impregnated with plant extracts on the test organisms. 
Table 2: Mean Zones of Inhibition (mm) of aqueous extracts of Chrysophyllum albidum fruit on some selected organisms.

\begin{tabular}{|l|c|c|c|}
\hline \multirow{2}{*}{ Organisms } & \multicolumn{3}{|c|}{ Zones of Inhibition(mm) } \\
\cline { 2 - 4 } & $25(\mathbf{m g} / \mathbf{m l})$ & $50(\mathbf{m g} / \mathbf{m l})$ & $100(\mathbf{m g} / \mathbf{m l})$ \\
\hline Staphylococcus aureus & 16.5 & 20.0 & 24.0 \\
\hline Klebsiella pneumonia & 10.5 & 12.0 & 15.0 \\
\hline Candida albicans & 11.0 & 13.0 & 15.5 \\
\hline Escherichia coli & 12.0 & 13.5 & 14.5 \\
\hline
\end{tabular}

Table 3: Mean Zones of Inhibition (mm) of methanolic extracts of Chrysophyllum albidum fruit on some selected organisms.

\begin{tabular}{|l|c|c|c|}
\hline \multirow{2}{*}{ Organisms } & \multicolumn{3}{|c|}{ Mean zones of inhibition(mm) } \\
\cline { 2 - 4 } & $50(\mathbf{m g} / \mathbf{m l})$ & $100(\mathbf{m g} / \mathbf{m l})$ & $200(\mathbf{m g} / \mathbf{m l})$ \\
\hline Staphylococcus aureus & 12.0 & 17.5 & 21.0 \\
\hline Klebsiella pneumonia & 10.5 & 11.5 & 14.0 \\
\hline Candida albicans & 11.5 & 14.0 & 16.5 \\
\hline Escherichia coli & 11.0 & 13.0 & 15.0 \\
\hline
\end{tabular}

\section{Minimum Inhibitory Concentrations (MIC)}

The table shows the Minimum Inhibitory Concentrations (MIC) of the test organisms which is the lowest concentration of the plant extracts which can inhibit the growth of the organisms as determined from the zones of inhibition.

Table 4: Minimum Inhibitory Concentrations (MIC) of the aqueous and methanolic extracts of Chrysophyllum albidum fruit on selected organisms.

\begin{tabular}{|l|c|c|}
\hline \multirow{2}{*}{ Organisms } & \multicolumn{2}{|c|}{ Minimum Inhibitory Concentration (mg/l) } \\
\cline { 2 - 3 } & Aqueous & Methanolic \\
\hline Staphylococcus aureus & 25 & 50 \\
\hline Klebsiella pneumonia & 25 & 50 \\
\hline Candida albicans & 25 & 50 \\
\hline Escherichia coli & 25 & 50 \\
\hline
\end{tabular}

\section{Discussions}

Phytochemicals are believed to confer antimicrobial property to plants. In this work, the analysis of the phytochemicals of the fruits of Chrysophyllum albidum, revealed the presence of Flavonoids, Steroids, Alkaloids, Tannin, Anthraquinone and Cardiac glycosides while Saponin was found absent. The results obtained in this work was in agreement to the work of Duyilemi and Lawal [10]. They also reported that the plant contains saponons Tanins and Anthraquinine. Analysis of a part of the fruit by Orijajogun et al [11] also agreed with the components seen in this research. Plants that contains alkaloids have been discussed extensively by researchers to be antibacterial [12]. Also, Plants containing polyphenols are associated with their antioxidant activities and good potentials as anti-inflammatory, anti-diarrheal and anti-hemorrhoidal compound $[11,13]$. Therefore, the presence 
of cardiac glycoside in C. albidum makes it to be likelihood in application in congestive heart failure as reported by Aboaba [14].

This plant also have antimicrobial activity. From the result of this research, it was observed that all the concentrations of both the aqueous and methanolic extracts showed clear zones of inhibition against the four pathogenic bacterial and fungal isolates tested, which are Staphylococcus aureus, Escherichia coli, Klebsiella pneumonia and Candida albicans respectively. This means that all four organisms are susceptible to the extracts of Chrysophyllum albidum fruit.

This agreed with the findings of Adewusi [15], who reported that the latex or exudates from $C$. albidum plants has antimicrobial properties against Staphylococcus aureus, Escherichia coli, Klebsiella pneumonia, Streptococcus pyogenes and Candida albicans. Okoli and Okere [16] also reported that $C$. albidum root extracts and stem slash successfully inhibited Pseudomonas aeruginosa, Escherichia coli, Staphylococcus aureus, C. tetani, Bacillus subtilis, and Candida albicans, while the seed cotyledon inhibited $C$. albicans. It is obvious that $C$. albidum fruit has similar antimicrobial activity as other parts of the plant as they inhibit virtually the same microorganisms.

The maximum activity of the aqueous extracts in the test isolates was observed on Staphylococcus aureus, which showed clear zones with diameters of $24.0 \mathrm{~mm}, 20.0 \mathrm{~mm}$ and $16.5 \mathrm{~mm}$ at concentrations of $100 \mathrm{mg} / \mathrm{ml}, 50 \mathrm{mg} / \mathrm{ml}$ and $25 \mathrm{mg} / \mathrm{ml}$ respectively. The lowest zone of inhibition for the aqueous extracts was observed on Klebsiella pneumonia, with clear zones of inhibition of $15.0 \mathrm{~mm}, 12.0 \mathrm{~mm}$ and $10.5 \mathrm{~mm}$ at same concentrations.

This results for the methanolic extracts also shown the same pattern. Once again, the highest zones of inhibition was observed on Staphylococcus aureus with clear zones of $21.0 \mathrm{~mm}, 17.5 \mathrm{~mm}$ and $12.0 \mathrm{~mm}$ at concentrations of $200 \mathrm{mg} / \mathrm{ml}, 100 \mathrm{mg} / \mathrm{ml}$ and $50 \mathrm{mg} / \mathrm{ml}$ respectively. Also, the lowest zones of inhibition were seen on Klebsiella pneumonia with clear zones of $14.0 \mathrm{~mm}, 11.5 \mathrm{~mm}$ and $10.5 \mathrm{~mm}$ at same concentrations. Thus, it can be inferred that Staphylococcus aureus is the most susceptible organism to both the aqueous and methanolic extracts of Chrysophyllum albidum fruit, while Klebsiella pneumonia is the least susceptible organism.

The type of extracts used in extraction also plays a role in the activity of Chrysophyllum albidum [17]. It is also pertinent to note that in this research, the aqueous extracts had greater activity than the methanolic extracts at same concentrations. For example, at $50 \mathrm{mg} / \mathrm{ml}$ the zones of inhibition for the aqueous extracts on Staphylococcus aureus, Escherichia coli, Klebsiella pneumonia and Candida albicans were $20.0 \mathrm{~mm}, 13.5 \mathrm{~mm}, 13.0 \mathrm{~mm}$ and $12.0 \mathrm{~mm}$ respectively while their corresponding inhibition zones for the methanolic extracts at the same concentration were $17.5 \mathrm{~mm}$, $13.0 \mathrm{~m}, 11.5 \mathrm{~mm}$ and $14.5 \mathrm{~mm}$ respectively. The Minimum Inhibitory Concentration (MIC) of both extracts was determined from the concentrations of the zones of inhibition, as $25 \mathrm{mg} / \mathrm{ml}$ for the aqueous extracts and $50 \mathrm{mg} / \mathrm{ml}$ for the methanolic extracts.

The results of the tests of both extracts were analysed with the analysis of variance (ANOVA). The probability of the result for aqueous extracts, assuming the null hypothesis was 0.245 . Thus, the null hypothesis was rejected because the result is significant at $(\mathrm{P}<1)$. Likewise, the result for the methanolic extracts, assuming the null hypothesis was 0.031 . Also, the null hypothesis was rejected as the result is significant at $(\mathrm{P}<1)$.

\section{Conclusion}

In conclusion, it was confirmed that the Chrysophyllum albidum fruit, specifically the pulp and peel also has antimicrobial properties against both bacterial and fungal isolates like other parts of the plant. This is because of its evident inhibition of the four pathogenic microbial isolates which were all susceptible to its aqueous and methanolic extracts. The antimicrobial activity could be because of the phytochemicals, bioactive compounds or principles in the fruit. This research therefore provides a scientific rationale for the traditional treatment of diseases with antimicrobial plants as well as the isolation and identification of the bioactive compounds. 


\section{Recommendation}

In cognizance of the problems of antibiotic resistance by many pathogenic microorganisms, it is expedient that the use of antimicrobial or medicinal plants be encouraged in the traditional treatment of diseases in place of antibiotics which have lost their potency. It is also encouraged that more plants be studied for possible antimicrobial properties and efficacy against all kinds of organisms. Furthermore, efforts should be made to go one step further to isolate and identify the bioactive compounds or principles present in these plants and subsequently determine its spectra and potency (Rios and Recio, 2005). Further research is also required to utilize these bioactive compounds in the ethnomedicinal or ethnopharmacological production of phytopharmaceuticals. Hence, all pharmaceutical companies are encouraged to establish research and development units to achieve this purpose.

\section{References}

[1]. Okorondu S. I., Adeleye, S. A. Okorondu, M. M. O. Review on medicinal plants. Nigerian journal of Microbiology, 29(2015) 3167-3183.

[2]. Petrovska, B.B.. History review of medicinal plants' usage. Pharmacognosy Review. 6 (11) (2012) 1-5.

[3]. Iwu, M.M., Duncan, A.R. and Okunji, C.O. New Antimicrobials of plant origin. In Janick, J. (ed) Perspectives in New crops and New uses. ASHS Press, Alexandria, V.A, 1999, Pp 457462.

[4]. Asaolu, M.F. Chemical composition and phytochemical screening of the seeds of Garcinia kola. Pakistan Journal of Science and industrial research, 46(2003) 145-147.

[5]. Ciulei, I. Practical Manuals on the Industrial Utilization of Medicinal and Aromatic plants, University of Bucharest, Romania (1964).

[6]. Chitravadivu, C., Manian, S. and Kalachelvi, K. Qualitative analysis of Selected Medicinal Plants, Tamilnadu, India. Middle East J. Sci. Res., 4(2009) 144-146.

[7]. AOAC. Official Methods of Analysis. Association of Official Analytical Chemists, 15th Edn., Washington D.C., USA (2010).

[8]. Buchanan, R. E. and Gibbon, N. E. . Bergey's Manual of Determinative Bacteriology. 8th ed. The Williams and Wilkin's Co. Baltimore, 1984, pp 1246-1249.

[9]. Cheesbrough, M. District Laboratory Practise in Tropical Countries Part 2. Cambridge University Press, Cambridge, United Kingdom, 2000, pp 38- 219.

[10]. Duyilemi, O.P and Lawal, I.O. Antibacterial activity and phytochemical screening of Chrysophyllum albidum leaves. As. J. Food Ag-Ind. Special issue. (2009) S75-S79

[11]. Orijajogun, O.J., Olajide, O.O., Fatokun, A.O., Orishadipe, A.T. and Batari, M.L. The Preliminary Chemical Constituents and Free Radical Scavanging Activities of The Exocarp of The Fruit Extract of African Star Apple (Chrysophyllum albidum G. Don). IJRPS, 3(3) (2013) $72-80$

[12]. Spencer, A.L.R., Spencer, J.F.T. Public Health Microbiology: Methods and Protocols. Human Press Inc. New Jersey, 2004, pp.325-327.

[13]. Kamba, A.S. and Hassan, L.G. Phytochemical screening and antimicrobial activities of African star Apple (Chrysophyllum albidum) leaves, stem against some pathogenic microorganism. Int. J. of Pharm. Frontier Research. 1(2) (2011) 119-129. 
[14]. Aboaba, O.O., Smith, S.T., Olide, F. O. Antimicrobial effect of Edible plant Extract on Escherichia.Coli, 0157:H7. Pak.J.Nutr. 5(4) (2006) 325-327

[15]. Adewusi, H.A. The African star apple Chrysophyllum albidum indigenous knowledge from Ibadan, Southwest Nigeria. In proceedings of a National worksop on the potentials of the star apple in Nigeria, 1997, pp 25-33.

[16]. Okoli, B.J. and Okere, O.S.. Antimicrobial activity of the phytochemical constituents of Chrysophyllum albidum G. Don Holl (African star apple) plant. Journal of Research in National development, 8(1) (2010) 11-16.

[17]. Ajetunmobi, A. O. and Towolawi, G. A. Phytochemical Analysis and Antimicrobial Effect of Chrysophyllum albidum Leave Extract On Gastrointestinal Tract Pathogenic Bacteria and Fungi in Human. IOSR Journal of Applied Chemistry (IOSR-JAC). 7 (1) (2014) 01-05

[18]. Rios, J.L. and Recio, M.C. Medicinal plants and antimicrobial activity. Journal of Ethnopharmacology, 100(2005) 80-84. 